\title{
Investigating Generation Z' Intention to Use Learners' Generated Content for Learning Activity: A Theory of Planned Behavior Approach
}

\author{
https://doi.org/10.3991/ijet.v15i04.11665 \\ Satria Fadil Persada ( $\bowtie$ ), Jeremy Ivanovski, Bobby Ardiansyah Miraja \\ Institut Teknologi Sepuluh Nopember, Surabaya, Indonesia \\ satriafadil@mb.its.ac.id \\ Reny Nadlifatin \\ Institut Teknologi Sepuluh Nopember, Surabaya Indonesia \\ Ilma Mufidah \\ Telkom University, Bandung, Indonesia \\ Jacky Chin \\ Universitas Mercu Buana, West Jakarta, Indonesia \\ A.A.N Perwira Redi \\ Universitas Pertamina, Jakarta, Indonesia
}

\begin{abstract}
Nowadays, learning media has developed rapidly, opening infinite possibilities for students to access their educational materials. Learner's Generated Content (LGC) is one of the emerging learning media that showed interesting promises. LGC is based on the concept of User Generated Content; many advantages of UGC also existed in LGC: speed, collaboration, and the diversity of contents. Although past researches have already proven that LGC has positive effects on the educational process, mainly, these previous researches focused only on the perspective of the educators. This study questioned how today's students, mostly comprised of Generation Z, see LGC. Employing the Theory of Planned Behaviour (TPB), we revealed several statistical results followed by managerial interpretations. Attitude (AT) was shown to have the highest correlation with Generation Z's students $(\beta=0.43)$, educators could utilise this fact; they can be more reassured when implementing LGC in their future curriculum. The Perceived Behavioral Control (PBC) was also significant towards our respondent's behavioural intention $(\beta=0.34)$, indicating that there is a little limitation for students to use LGC as part of their learning activity.
\end{abstract}

Keywords - LGC, TPB, Generation Z, Learning Media, SEM 


\section{Introduction}

The digital revolution sets off many development and innovation in various fields. The internet, for example, having the initial purpose of creating worldwide networks of information, has been able to provide many improvements for any kinds of problems: from the relatively simple development such as the digitalisation of paper-based newspaper to complex technology creation such as e-commerce. However, not many realised that there is another critical factor that supported these advancements: the Web 2.0 [1], it is the answer for the old question of "How internet could create worldwide networks of information?" [2]. Web 2.0 transformed the internet to become how it is today, a more collaborative and interactive network of information [2] [3]. This means that every internet user can actively participate in the process of creation, dissemination, and the exchange of information. When a user participates in this process, any new information created by them is known as User Generated Content (UGC) [4]. The existence of the web and UGC changed how information is spread, from Business to Consumer (B2C) to Peer-to-peer (P2P) [5]. UGC encourages content creations to shift from the previously dominated by professional creators to a more inclusive one [6]; this made UGC became today's most massive and consumed source of information [7]. UGC's growth into its existence today is also supported by eWOM (electronic Word of Mouth), while UGC is the content, eWOM is the main tools for UGC's distribution [8]. The Web 2.0 and UGC existed side-by-side with Generation $Z$. Born with almost infinite connectivity, Generation $\mathrm{Z}$ is very active on the internet [9]. This particular characteristic of Generation $Z$ created an integration between the internet and Generation Z, a behavioural shift of how Generation $Z$ processed information was also apparent [10]. Generation $Z$ is commonly described as instantminded and has faster life rhythm [11], these characteristics are not necessarily a problem, in fact, it can be seen as a positive effect of Web 2.0 and UGC. Systematic changes follow the UGC and its impact on Generation Z information processing in multiple areas such as marketing, entertainment, and even education. In today's marketing, the value proposition aspect of products can be experienced without needing to purchase it first because of the overwhelming information available on the internet, and especially in the UGC [12]. In the entertainment industries, UGC expanded the available contents so that entertainment needs became more personalised [13]. Directly correlated with the availability of information, education gained an acceleration from the UGC. Today's education is focused on more meaningful teaching with less bureaucracy restraining the educational process [14]. A 'class' with its syllabuses can become more irrelevant; it limits the number of information media used in the learning process. The traditional education system such as this is more abandoned because of the fundamental inefficiencies of this type of teaching and the massive resource needed compared to future educational methods [15]. The massively available UGC contents presented opportunities for the educational systems to accommodate the disadvantages of traditional teaching. Internet as the medium has to be adopted sooner by educational institutions so that Learners Generated Content (LGC) become more dominant in the educational settings [16, 17]. Past pieces of research have discussed how educational institutions should respond to LGC. However, the majority of these 
research pieces focused on the educator or the institution's point of view on how to upgrade their teaching systems or shifting their pedagogical methods $[18,19]$. In the present research, we intend to answers how LGC is responded by the students in Generation Z. We employed the Theory of Planned Behavior (TPB), a well-known model to investigate the intention of a sample, where behavioral intention can be interpreted by three main factors: Attitude, Subjective Norms, and Perceived Behavioral Control [20]. Understanding the Generation $Z$ perception could complement the current growing trend of utilizing the LGC in the educational settings. The result of this study is expected to have a practical implications for educational institutions and even the regulators.

\section{$2 \quad$ Literature Review}

This chapter explains the underlying theory of each variable and the relationship between them. The first sub-chapter defines Generation $\mathrm{Z}$ and their unique characteristics. The second sub-chapter defines the Learner's Generated Content or LGC, its attributes, and an example. The next sub-chapter describes the Theory of Planned Behavior (TPB), and how this framework is suitable for our research's purpose.

\subsection{Generation Z}

Individual behavior can be affected by demographical factors; one of them is the time of birth. Individuals with the same birth range tend to have similar characteristics [21]. Generation $\mathrm{Z}$ is the demographical group born between mid-1990 to early 2000 . This generation tends to work smarter and faster because of how today's information seeking is almost an effortless activity [22, 23]. This effortless information-seeking process is mainly attributed to the development of the internet; Generation $\mathrm{Z}$ was born with the already matured internet, making them also known as the internet generation [24]. Generation $\mathrm{Z}$ and the internet have become more integrated, supported with the availability of smartphones which act as the primary tool to connect with the internet [25]. This particular characteristic of Generation $Z$ also created another label that Generation $Z$ is identified with, the "Mobile and App Native" Generation. Generation $\mathrm{Z}$ is also known for their ability to rapidly locate only specific information they needed, making the internet, and especially the LGC as the perfect place for them to enhance their learning process [26]. At an individual level, Generation $\mathrm{Z}$ is known to have open-mindedness traits to things; this includes new learning technologies such as blended learning, e-learning, and the LGC [27].

\subsection{Learners' generated content}

A type of UGC which is mainly used for educational purposes has its own term: Learners Generated Content (LGC). The LGC makes the learning activities easier because it provides a collaborative environment, where students can efficiently learn by exchanging learning materials with other students across the world [28]. The col- 
laborative learning that LGC provided act as a stimulant for successful active learning. Active learning is the involvement of students and their thought process in the learning activities, which has proven to increase learning quality [29]. Generation Z plays a vital role in the development of LGC; they are the majority of today's students, and they are the most technologically fluent generation to have access to the LGC [30].

LGC is supported by the psychological aspect of how an individual needed to be known and have the urge to share something. This aspect acts as a natural incentive for an individual, or in this context a learner, to create educational contents. Learners could easily share their content via different platforms such as YouTube, Blogs, Wikis, Quora, and other platforms that enable LGC. [31]. The opportunity to share a learner's knowledge, and in turn creating LGC, also enhances their learning process. By sharing their knowledge and creating LGCs, students are practising the 'learning by teaching' approach to learning [32]. LGC attracts many of today's learner; it is mainly attributed to how simple the concept of LGC is and how today's learners are more accustomed to 'easy' language and informal discussions; both present in LGC [33]. An example of an LGC content is illustrated in Figure 1.

\section{How do I read an income statement?}

Jeremy Kruid, Author at Momentum Trading (2019-present)

Answered Mar 24

Here is a simple overview of a Apples income statement from my blog at How to Invest in stocks [a] :

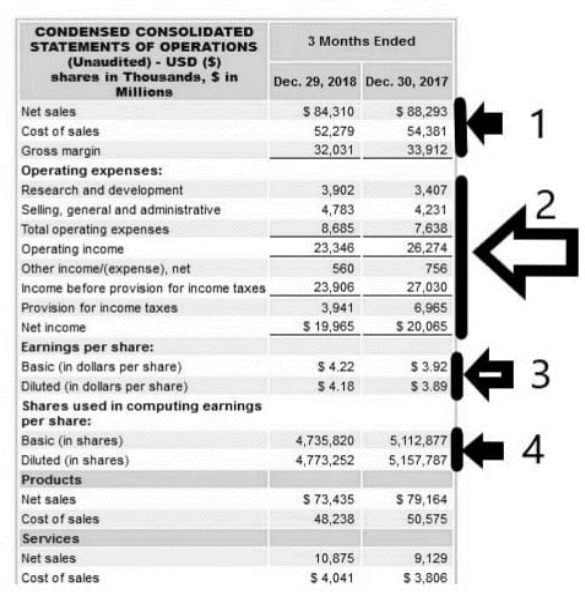

Welcome to the next part in my What is a stock Series. In this section we will be talking about how to read an income statement. For this example we

Fig. 1. An LGC found in quora.com 


\subsection{Theory of planned behavior}

Describing human behaviour is a challenging task, but few approaches exist to asses this challenge, one of the most used approaches is psychological. A psychological approach to understanding human behaviour is popular because human, in nature, exhibits patterns. These patterns then could be analysed using statistical procedures and the output of a theoretical model will be formulated. The Theory of Planned Behaviour (TPB) is one of the most well-known theoretical models. TPB was originally developed from the existing Theory of Reasoned Action (TRA). Employing the Structural Equation Modeling (SEM), the TPB model can explain human behaviour by analysing their various underlying behavioural dispositions: their personal views on a concept (attitude), social attitude (subjective norm), and cognitive self-regulation (perceived behavioural control) [34]. These behavioural dispositions do not directly predict the actual behaviour of a person; instead, a bridge connecting the two was usually present: behavioural intention (BI). Behavioural Intention (BI) is the measure of an individual's willingness or motivation to do something. The bigger the $\mathrm{BI}$ is, the bigger the probability of actual behaviour [35]. For its many advantages and fitness in explaining factors affecting an individual's decision to do a particular action, in this case, the intention to use LGC, we proposed the use of TPB for this study. Figure 2 shows the TPB framework we used for the present research.

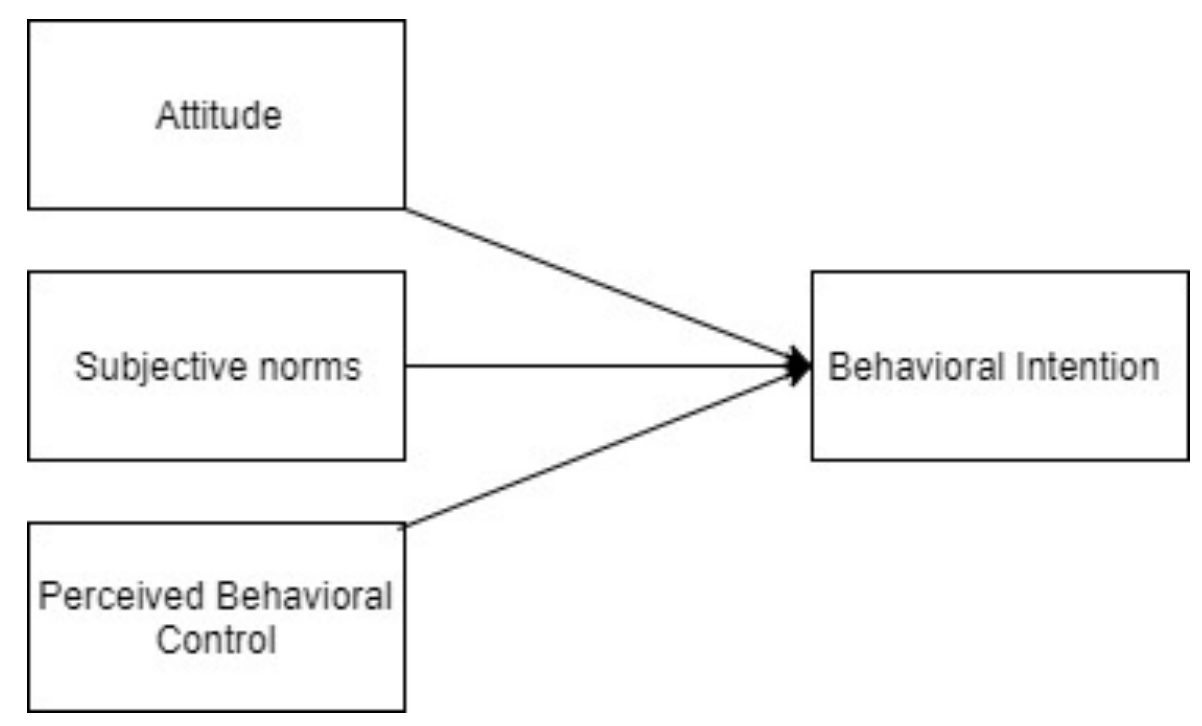

Fig. 2. The TPB Framework

\subsection{Hypotheses development}

The BI, acting as the bridge for actual behaviour, has three determinants in the TPB model: Attitude (AT), Subjective Norm (SN), and Perceived Behavioral Control (PBC). AT represents an individual's views on a particular subject, $\mathrm{SN}$ represents how 
far the social condition for an individual could affect their behaviour, and lastly, PBC represents an individual's beliefs on how they control themselves [37]. PBC covers not only the self-efficacy aspect, the ability to do a particular action; the availability of facilities and opportunities are also an essential part of PBC [38]. The PBC factor was formulated to perfect the Theory of Reasoned Action (TRA) which assumed that every person has equal capabilities to control their actions [39]. Using the three factors inside the TPB model, understanding Generation Z's behavioural intention towards LGC is possible. Hypotheses were formulated using the model; four hypotheses were used and explained in detail as follows:

The influence of AT to generation $Z$ ' intention: If Generation $Z$ has a positive evaluation of LGC, we hypothesised that their intention to use LGC in their learning activity would increase. This is caused by how the selection of a learning media is also based on how an individual evaluates it. When a student does not like the concept of a paper-based book, for example, it is possible that they would not intend to use a paper-based book as a learning media and vice versa. [40]. Furthermore, past research also showed that there is a positive correlation between positive evaluation (AT) of Web 2.0 and the intention to use it as a supporting learning media. LGC, being a part of Web 2.0 enabled media, can also exhibit this positive relationship. Thus, the first hypothesis for this research is:

H1: AT has a positive effect on Generation Z's intention to use LGC.

The influence of SN to Generation Z' Intention: $\mathrm{SN}$ in this research shows how significant is the effect of peers, teachers, and family members opinions to the respondent's perspective of LGC. Being very active in social media, Generation Z could consider others opinion more. This is important, especially in this context, considering how LGC exhibited interaction and collaboration aspects in its core [41]. Furtherly, in some cases, LGC is even driven by the existence of social media, making Subjective Norms (SN) of others could affect Generation Z intention to use LGC more frequent. Therefore, the second hypothesis is:

H2: SN has a positive effect on Generation Z's intention to use LGC.

The influence of PBC to Generation $Z$ ' Intention: The PBC explains a person's view of their self-regulation strength. Self-regulation is an individual perception of whether or not they are able to do a particular task. The concept of PBC encompasses two main factors: control belief and the feeling of being facilitated. If an individual has a belief of control of a particular action or task, they will be more confident in doing the task and in turn, could see the task as a favourable action to do. This also applies to Generation $Z$ and their control belief of LGC. Because LGC contents are also created by other Generation $Z$ learners, which resulted in a content's contextual presentation and language style similarity, a Generation $\mathrm{Z}$ student can have a higher control belief in their ability to use LGC media. In the facilitating condition perspective, Generation $Z$ could have a higher intention to use LGC when they feel that they have adequate facilities and resources to access LGC contents. This is possible because Generation $\mathrm{Z}$ has enough experience with technology and the internet, which is the main foundation of the LGC. Therefore, the last hypothesis is proposed:

H3: PBC has a positive effect on Generation Z's intention to use LGC.

The proposed model from the hypotheses developed is shown in Figure 3. 


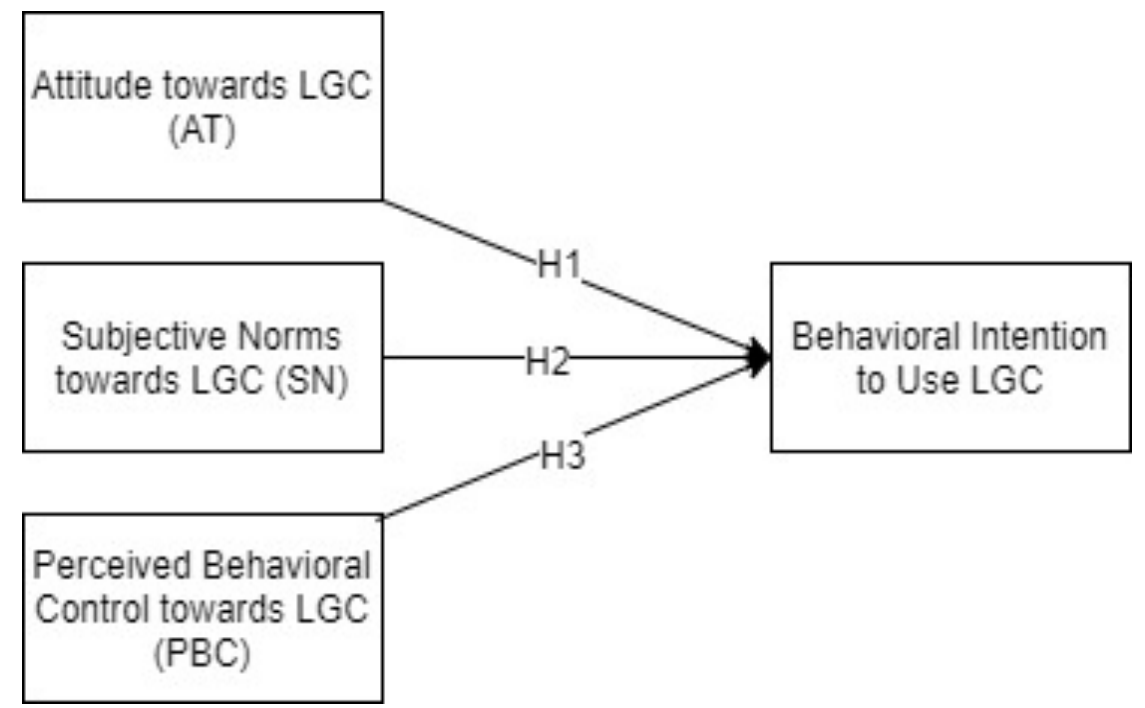

Fig. 3. The Proposed Model

\section{Research Methodology}

In order to explain the underlying factors influencing Generation Z's intention to use LGC, we used Confirmatory Factor Analysis (CFA) and Structural Equations Modelling (SEM). CFA is used when a model that has been well developed is tested against empirical data. The result of the CFA concluded the present research; therefore, this study was considered as conclusive research. The conclusion of this study is expected to open up new perspectives for the educators in taking a managerial decision in the future. In connection with the prevalence of a group, this study used a multiple cross-sectional design sampling approach; the differences in respondent's institutions lead to multiple rather than single cross-sectional designs. The sampling technique used is non-probabilistic sampling, a purposive one, where the respondents are limited to specific criteria to achieve the research objectives; in this study, the main criteria for respondents were their generational identities: Generation Z. The media used to collect the respondents' data is online questionnaires. The questionnaires consisted of two parts, the first part is concerned with the demographical and introductory questions and the second part is filled with 18 questions that measure the 4 TPB model variables. See Table 1 for the complete list of questionnaire items. 
Table 1. Questionnaire Items and Variable Correlations

\begin{tabular}{|c|c|c|c|}
\hline Variable & Question & Variable & Question \\
\hline AT1 & $\begin{array}{l}\text { In my opinion, using LGC will } \\
\text { facilitate me in learning. }\end{array}$ & PBC1 & I believe I have the ability to use LGC \\
\hline AT2 & $\begin{array}{l}\text { I like the concept of using LGC } \\
\text { as a learning media }\end{array}$ & PBC2 & I believe I can use LGC optimally \\
\hline AT3 & $\begin{array}{l}\text { I have a positive attitude towards } \\
\text { LGC as a learning media }\end{array}$ & PBC3 & $\begin{array}{l}\text { If I use LGC, I think it's of my own } \\
\text { volition }\end{array}$ \\
\hline AT4 & $\begin{array}{l}\text { I believe that LGC enables me to } \\
\text { accomplish tasks more quickly }\end{array}$ & PBC4 & $\begin{array}{l}\text { I have facilities (internet, device, etc.) } \\
\text { that are sufficient to use LGC }\end{array}$ \\
\hline AT5 & $\begin{array}{l}\text { In my opinion, } \mathrm{LGC} \text { will make } \\
\text { me more comfortable in learning }\end{array}$ & PBC5 & $\begin{array}{l}\text { If I free to choose my main source of } \\
\text { materials, I will choose LGC. }\end{array}$ \\
\hline SN1 & $\begin{array}{l}\text { I think my parents and friends } \\
\text { considering LGC as a positive } \\
\text { learning media for me }\end{array}$ & BI1 & I plan to use LGC in the next one year. \\
\hline SN2 & $\begin{array}{l}\text { I think the people closest to me } \\
\text { considering LGC as a positive } \\
\text { learning media for me }\end{array}$ & $\mathrm{BI} 2$ & $\begin{array}{l}\text { I intend to use LGC in the next one } \\
\text { year. }\end{array}$ \\
\hline SN3 & $\begin{array}{l}\text { I think my lecturer and classmate } \\
\text { considering LGC as a positive } \\
\text { learning media for me }\end{array}$ & $\mathrm{BI} 3$ & $\begin{array}{l}\text { I would try to use LGC in the next } \\
\text { year }\end{array}$ \\
\hline SN4 & $\begin{array}{l}\text { People who are important to me } \\
\text { agree that LGC is beneficial for } \\
\text { me }\end{array}$ & BI4 & I intend to recommend LGC to others \\
\hline
\end{tabular}

The data that has been collected was then modeled and tested afterwards. This study examined the data in the form of structural equation modelling (SEM); the TPB model was used with three hypotheses. Before testing the model, firstly, we tested the data to see whether the data meets the elements of validity and reliability. We used three measures namely Cronbach $\alpha$, Composite Reliability (CR), and Average Variance Extracted (AVE). The minimum value that must be achieved to pass the data are $0.7,0.7$, and 0.5 for each test. To test the fitness of the model, we employed some of the most popular model-fit measures: Goodness of Fit (GFI), Comparative Fit Index $(\mathrm{CFI})$, and Normed Fit Index (NFI) each with the minimum values of 0.8 required.

\section{$4 \quad$ Result Analysis and Discussion}

This chapter provides the analysis from the data we have collected. The first subchapter, demographics, explains the profiles of the respondents participating in this study. The next sub-chapter, data analysis, describes the statistical results extracted from different statistical procedures we employed. Next, we discussed the results from the previous sub-chapter and made some inferences. Lastly, the last two subchapters presented practical implication for educators and theoretical implications for future researches.

\subsection{Demographics}

The research questionnaire was distributed for two months, starting from mid-May 2019 to Mid July 2019. There were 167 data in accordance with the previously set 
criteria collected from 172 respondents. Respondents were spread across 30 regions in Indonesia. Based on gender, respondents of the questionnaire were at a percentage of $51.7 \%$ female, $45.3 \%$ male, and $2.9 \%$ chose not to answer. To ensure that the respondent understood the main object of research equally, we provided a brief description of the LGC. Most respondents had experience with LGC for more than five years (56.9\%) followed by the second most, 3-5 years (20.4\%). This result is not surprising because their interaction with LGC has been very easy, especially in the digital era and with the emergence of smartphones. Respondents admitted that they access LGC content using smartphones (90\%), a typical Generation $\mathrm{Z}$ trait: making smartphones as the center of their activities.

\subsection{Data analysis}

Since we used the CFA to complement the SEM in our study, two measurements testing will be conducted, both the data testing and model testing were done by using the IBM SPSS Statistics 25 and the IBM SPSS AMOS 20. Data testing were done to measure several statistical measurement aspects: Factor Loading (FL), Average Variance Extracted (AVE), Composite Reliability (CR), and Cronbach's $\alpha$. FL is defined as an item-factor relationship that is seen to have a pattern, the higher the factor loading value, the higher the questionnaire correlation with latent construct, a minimum value that is commonly used by past pieces of research is 0.6 [43, 44]. Average Variance Extracted is defined as the average value of variants, it represents how diverse the data was spread from the questionnaire items and ultimately, how is the convergent validity of the variables in the data. The minimum value required for this measurement is 0.5 [45]. Another convergent validity measures, the Composite Reliability, was also used. CR is defined as the total of true variation's score in relation to the total score variance [46]; we used the most commonly used standard minimum value for $\mathrm{CR}$ which is 0.7 . Lastly, acknowledging the importance of data reliability, especially for research related to human psychology such as the present research, Cronbach's $\alpha$ was used. The internal consistency of a set of indicators can be measured by using the Cronbach $\alpha$, the minimum required value for this measure is 0.6. [47].

Table 2 displays the results of the previously described data measurements testing, along with the minimum value for each benchmark. Factor loadings for the AT items have the value higher than 0.7. SN's items have loadings higher than 0.6. All of PBC's loadings are higher than 0.7. BI has the highest overall loadings; all surpassed 0.9. Results for the AVE measurements all surpassed the minimum value of 0.5 , showing a convergent validity. The convergent validity is also supported by the CR values; all variables showed $\mathrm{CR}$ values higher than the minimum required value (0.7). Finally, Cronbach's $\alpha$ results also surpassed the minimum value set previously. 
Table 2. Reliability and Validity Measurement Result

\begin{tabular}{|c|c|c|c|c|c|}
\hline Variable & Item* & $\begin{array}{c}\text { Factor Load- } \\
\text { ing }(>0.6) \\
{[43][44]}\end{array}$ & $\begin{array}{c}\operatorname{AVE}(>0.5) \\
{[45]}\end{array}$ & $\begin{array}{c}\text { Composite } \\
\text { Reliability (> } \\
\text { 0.7) [47] }\end{array}$ & $\begin{array}{c}\text { Cronbach's } \alpha \\
(>0.7)[47]\end{array}$ \\
\hline \multirow{4}{*}{ Attitude } & A1 & 0.77 & \multirow{4}{*}{0.65} & \multirow{4}{*}{0.88} & \multirow{4}{*}{0.879} \\
\hline & A2 & 0.862 & & & \\
\hline & A3 & 0.83 & & & \\
\hline & A4 & 0.764 & & & \\
\hline \multirow{3}{*}{$\begin{array}{l}\text { Subjective } \\
\text { Norms }\end{array}$} & SN1 & 0.62 & \multirow{3}{*}{0.53} & \multirow{3}{*}{0.76} & \multirow{3}{*}{0.764} \\
\hline & SN2 & 0.759 & & & \\
\hline & SN3 & 0.793 & & & \\
\hline \multirow{3}{*}{$\begin{array}{c}\text { Perceived } \\
\text { Behavioral } \\
\text { Control }\end{array}$} & PBC1 & 0.749 & \multirow{3}{*}{0.53} & \multirow{3}{*}{0.76} & \multirow{3}{*}{0.767} \\
\hline & PBC2 & 0.7 & & & \\
\hline & PBC3 & 0.735 & & & \\
\hline \multirow{3}{*}{ Intention } & BI1 & 0.910 & \multirow{3}{*}{0.53} & \multirow{3}{*}{0.77} & \multirow{3}{*}{0.965} \\
\hline & $\mathrm{BI} 2$ & 0.972 & & & \\
\hline & $\mathrm{BI} 3$ & 0.93 & & & \\
\hline
\end{tabular}

*Items with low factor loading were not included, and model respecification was then conducted

After data measures were tested, because of the collected data was modeled into an SEM model, it is necessary to test the model. Testing the model for fitness is known as a model-fit test. As the name suggests, the model-fit primary function is to evaluate whether or not the theoretical framework modeled fit the data. Model fit The TPB model we employed in our research was tested using two model-fit indices: Absolute Fit Indices and Incremental Fit indices. For the Absolute Fit Indices, we used the goodness-of-fit Index (GFI). The normed fit index (NFI) and the comparative fit index (CFI) were used for the incremental fit indices. The difference between the two categories lies in the calculation process; absolute fit indices are based on the variations in the data set and its relation to the sample. Meanwhile, the incremental fit index indices' calculation are based on the comparison with a baseline model [48]. Table 3 shows the value of model fit parameters result.

Table 3. Model Fit Results

\begin{tabular}{|l|c|}
\hline \multicolumn{1}{|c|}{ Indices } & Result [49-51] \\
\hline CFI & .8 \\
\hline GFI & .8 \\
\hline NFI & .8 \\
\hline
\end{tabular}

*All indices showing appropriate fit

Table 4 shows the estimated value and the significance level between each latent constructs. To see the significance level, we performed a bootstrap using 1000 dummy samples, the result of this bootstrapping is a value of significance, representing a correlation's probability in having inconsistent effect when different sub-samples were tested. A correlation is significant when the significance level is below 0.05 . Therefore, statistically, it can be concluded that the second hypothesis (SN) of this study was rejected ( $\mathrm{p}=0.318$ ). In contrast to $\mathrm{SN}$, the first hypothesis (AT) and the third hypothesis $(\mathrm{PBC})$ shows significant results. The p-value of AT is 0.004 and the pvalue of $\mathrm{PBC}$ is 0.028 , both meets the minimum significance level requirements. AT 
is significant with the estimated value of 0.43 , showing a considerable effect on BI. $\mathrm{PBC}$ is also showing a positive effect, with an estimated value of 0.34 . Table 3 represents the value of model fit in this study meeting or approaching the minimum graduation requirements of 0.8 .

Table 4. Hypothesis Testing

\begin{tabular}{|l|c|c|}
\hline \multirow{2}{*}{ Correlation between factor } & \multicolumn{2}{|c|}{ Direct correlation } \\
\cline { 2 - 3 } & Estimate ( $\boldsymbol{\beta})$ & Significance (p) \\
\hline $\mathrm{I} \leftarrow \mathrm{A}$ & .43 & .004 \\
\hline $\mathrm{I} \leftarrow \mathrm{SN}$ & .18 & .316 \\
\hline $\mathrm{I} \leftarrow \mathrm{PBC}$ & .34 & .028 \\
\hline
\end{tabular}

\subsection{Discussion}

This study seeks to provide a perspective especially from the main user of today's education: students of Generation Z. From the result, we can see that Generation Z's intention to use LGC positively correlated with two out of three of the constructs, AT and PBC. AT's positive effects exhibited a relatively high estimate $(\beta \mathrm{AT} \rightarrow \mathrm{BI}=0.43)$. This implies that Generation $Z$ positively evaluates the concept of LGC, they see LGC as a decent learning media and is useful for their learning activity. The relationship between AT and BI could be caused by how the majority of Generation $\mathrm{Z}$ is accustomed to the internet; increasing their familiarity and in turn, their positive evaluation towards the LGC. SN was found to have an insignificant effect $(\beta S N \rightarrow B I=0.18)$ on Generation Z's BI to use LGC. The absence of the significant relationship between $\mathrm{SN}$ and BI implies that Generation $\mathrm{Z}$ does not consider greatly the opinions of their peers and trusted people around them when intending to use LGC. A possible justification for this is how Generation $\mathrm{Z}$ is a more individualist compared to other generation, making SN and its aspects (social pressure, opinions of others) insignificant for their decision making, in contrast with our previous hypothesis. $\mathrm{PBC}$ also has significant effects on Generation Z's BI with a considerable estimate $(\beta \mathrm{PBC} \rightarrow \mathrm{BI}=0.34)$. The relationship between PBC and BI implies that Generation $Z$ perceives that they have the needed resources, knowledge, and facilities in using LGC. This is possible because Generation $\mathrm{Z}$ has unlimited access to technologies and the internet which is the foundation of LGC.

\subsection{Managerial interpretation}

The results of this study reassure today's educator to adapt LGC as a part of learning activity, seeing that Generation Z's students already have a positive outlook on LGC. Educators could also encourage students to generate LGC of their own, which could increase their understanding of the materials and their flexibility to use technology, this is furtherly supported by the high correlation between $\mathrm{PBC}$ and $\mathrm{BI}$, proving that Generation $\mathrm{Z}$ sees themselves to be capable of using LGC entirely and followingly, generate their own contents. However, just as how educators are also encouraged to be more careful in evaluating and selecting the right educational app, educators 
should also carefully evaluate the selection of LGC platforms in order to avoid contents that give less conceptual understanding.

LGC platform developers should also understand their products so that learning value can be delivered more effectively [53]. The developers should also improve their LGC platform including but not limited to: contents, design, or features. These improvements can increase the positive evaluation (attitude) towards LGC from the perspective of Generation Z, thus maintaining Generation Z's intention to use LGC. Considering that Generation $\mathrm{Z}$ has high $\mathrm{PBC}$ correlation to their intention and insignificant $\mathrm{SN}$ correlation to their intention, Generation $\mathrm{Z}$ can be seen as more individual learners; therefore more personalised learning algorithm for LGC contents recommendation is encouraged. Despite all of these LGC improvement recommendations, LGC developers should also consult with an educational expert so that LGC could also contribute to a deeper conceptual understanding [54].

\subsection{Theoretical implication}

In this research, TPB showed its effectiveness in explaining the Generation Z's intention to use LGC so that academics gained more understanding regarding this subject. However, the rapid developments of LGC should be considered more. Current Web 2.0 based LGC could quickly evolve to a more mobile app oriented LGC, in this case, a better framework in explaining technology adoption could be considered in future research addressing this topic. Future research could also address the content aspect of LGC, giving educators more understanding about how to integrate their curriculum with LGC in a better way.

\section{Conclusion}

This research investigated the behavioural intention of Generation $Z$ to use LGC to supports their learning activity. The result showed that Generation $Z$ has a positive intention to use LGC, with the significant factors of Attitude and Perceived Behavioral Control. The TPB model was proven to be a reliable model for understanding many aspects of human behaviour, and in this case, it also successfully explains the behavioural intention of Generation $\mathrm{Z}$ to use LGC. The effectiveness of the TPB model was also supported by the substantial value of the Squared Multiple Correlations (38\%), meaning that the TPB model could illustrate $38 \%$ of the factors influencing Generation Z's intention to use LGC.

Furthermore, in regard to the emergence of LGC, the result of this study indicated that educational institution should strategically implement new, more adaptive curriculum design to improve student's intention of using LGC. However, any new curriculum should be within the student's comfort level. Other recommendations were also presented in this study. 


\section{References}

[1] R. A. Peterson, S. Balasubramanian, and B. J. Bronnenberg, "Exploring the implications of the Internet for consumer marketing," Journal of the Academy of Marketing science, vol. 25, no. 4, p. 329, 1997. https://doi.org/10.1177/0092070397254005

[2] S. Murugesan, "Understanding Web 2.0," IT Professional Magazine, vol. 9, no. 4, p. 34, 2007.

[3] Q. Ye, R. Law, B. Gu, and W. Chen, "The influence of user-generated content on traveler behavior: An empirical investigation on the effects of e-word-of-mouth to hotel online bookings," Computers in Human behavior, vol. 27, no. 2, pp. 634-639, 2011. https://doi.org/10.1016/j.chb.2010.04.014

[4] A. Hermida and N. Thurman, "A clash of cultures: The integration of user-generated content within professional journalistic frameworks at British newspaper websites," Journalism practice, vol. 2, no. 3, pp. 343-356, 2008. https://doi.org/10.108 $\underline{0 / 17512780802054538}$

[5] P. O'Connor, "User-generated content and travel: A case study on Tripadvisor. com," Information and communication technologies in tourism 2008, pp. 47-58, 2008. https://doi. org/10.1007/978-3-211-77280-5 5

[6] T. Daugherty, M. S. Eastin, and L. Bright, "Exploring consumer motivations for creating user-generated content," Journal of interactive advertising, vol. 8, no. 2, pp. 16-25, 2008. https://doi.org/10.1080/15252019.2008.10722139

[7] G. Shao, "Understanding the appeal of user-generated media: a uses and gratification perspective," Internet research, vol. 19, no. 1, pp. 7-25, 2009. https://doi.org/10.1108 $\underline{10662240910927795}$

[8] H. J. Cheong and M. A. Morrison, "Consumers' reliance on product information and recommendations found in UGC," Journal of Interactive Advertising, vol. 8, no. 2, pp. 3849, 2008. https://doi.org/10.1080/15252019.2008.10722141

[9] E. J. Cilliers, "The challenge of teaching generation Z," PEOPLE: International Journal of Social Sciences, vol. 3, no. 1, 2017.

[10] E. Constantinides and S. J. Fountain, "Web 2.0: Conceptual foundations and marketing issues," Journal of direct, data and digital marketing practice, vol. 9, no. 3, pp. 231-244, 2008. https://doi.org/10.1057/palgrave.dddmp.4350098

[11] S. P. Desai and V. Lele, "Correlating internet, social networks and workplace-a case of generation Z students," Journal of Commerce and Management Thought, vol. 8, no. 4, p. 802, 2017. https://doi.org/10.5958/0976-478x.2017.00050.7

[12] R. Miller and N. Lammas, "Social media and its implications for viral marketing," Asia Pacific Public Relations Journal, vol. 11, no. 1, pp. 1-9, 2010.

[13] C. Riegner, "Word of mouth on the web: The impact of Web 2.0 on consumer purchase decisions," Journal of advertising research, vol. 47, no. 4, pp. 436-447, 2007. https://doi.org/10.2501/s0021849907070456

[14] S. Brand-Gruwel, I. Wopereis, and A. Walraven, "A descriptive model of information problem solving while using internet," Computers \& Education, vol. 53, no. 4, pp. 12071217, 2009. https://doi.org/10.1016/j.compedu.2009.06.004

[15] S. Wheeler, P. YEoMAnS, and D. WHEElER, "The good, the bad and the wiki: Evaluating student-generated content for collaborative learning," British journal of educational technology, vol. 39, no. 6, pp. 987-995, 2008. https://doi.org/10.1111/j.14678535.2007.00799.x 
[16] P.-N. Chou and H.-H. Chen, "Engagement in online collaborative learning: A case study using a web 2.0 tool," Journal of Online Learning and Teaching, vol. 4, no. 4, pp. 574-582, 2008.

[17] S. S. Mustapha, "Building Learning System for Content Knowledge and Social Knowledge," International Journal of Emerging Technologies in Learning (iJET), vol. 13, no. 1, pp. 4-22, 2018. https://doi.org/10.3991/ijet.v13i01.6912

[18] C. McLoughlin and M. Lee, "Social software and participatory learning: Pedagogical choices with technology affordances in the Web 2.0 era," 2007.

[19] C. McLoughlin and M. J. Lee, "Future learning landscapes: Transforming pedagogy through social software," Innovate: Journal of Online Education, vol. 4, no. 5, 2008.

[20] K. Mathieson, "Predicting user intentions: comparing the technology acceptance model with the theory of planned behavior," Information systems research, vol. 2, no. 3, pp. 173191, 1991. https://doi.org/10.1287/isre.2.3.173

[21] V. Jones, J. Jo, and P. Martin, "Future Schools and How Technology can be used to support Millennial and Generation-Z Students," in ICUT 2007 (Proc. B), 1st Int. Conf. Ubiquitous Information Technology, 2007, pp. 886-891: Citeseer.

[22] C. Igel and V. Urquhart, "Generation Z, meet cooperative learning: Properly implemented cooperative learning strategies can increase student engagement and achievement," Middle School Journal, vol. 43, no. 4, pp. 16-21, 2012. https://doi.org/10.1080/0 0940771.2012 .11461816

[23] S. F. Persada, B. A. Miraja, and R. Nadlifatin, "Understanding the Generation Z Behavior on D-Learning: A Unified Theory of Acceptance and Use of Technology (UTAUT) Approach," International Journal of Emerging Technologies in Learning, vol. 14, no. 5, 2019. https://doi.org/10.3991/ijet.v14i05.9993

[24] A. Turner, "Generation Z: Technology and social interest," The Journal of Individual Psychology, vol. 71, no. 2, pp. 103-113, 2015.

[25] M. Ozkan and B. Solmaz, "Mobile addiction of generation $z$ and its effects on their social lifes:(An application among university students in the 18-23 age group)," Procedia-Social and Behavioral Sciences, vol. 205, pp. 92-98, 2015. https://doi.org/10.10 16/j.sbspro.2015.09.027

[26] D. Rothman, "A Tsunami of learners called Generation Z," URL: http://www. mdle. net/JoumaFA_Tsunami_of_Learners_Called_Generation_Z.pdf, 2016.

[27] E. Loveland, "Instant generation," Journal of college admission, vol. 235, pp. 34-38, 2017.

[28] X. Yang, X. Guo, and S. Yu, "Student-generated content in college teaching: content quality, behavioural pattern and learning performance," Journal of Computer Assisted Learning, vol. 32, no. 1, pp. 1-15, 2016. https://doi.org/10.1111/jcal.12111

[29] A. F. Doubleday and S. J. Wille, "We are what we do: Examining learner-generated content in the anatomy laboratory through the lens of activity theory," Anatomical sciences education, vol. 7, no. 5, pp. 361-369, 2014. https://doi.org/10.1002/ase.1434

[30] C. Orús, M. Barlés, D. Belanche, L. Casaló, E. Fraj, and R. Gurrea, "The use of YouTube as a tool for learner-generated content: Effects on students' learning outcomes and satisfaction," Computers \& Education, vol. 95, pp. 254-269, 2016. https://doi.org/10.1016/j .compedu.2016.01.007

[31] M. J. Lee and C. McLoughlin, "Teaching and learning in the Web 2.0 era: Empowering students through learner-generated content," International journal of instructional technology and distance learning, vol. 4, no. 10, pp. 21-34, 2007.

[32] M. Pérez-Mateo, M. F. Maina, M. Guitert, and M. Romero, "Learner generated content: Quality criteria in online collaborative learning," European Journal of Open, Distance and E-Learning, vol. 14, no. 2, 2011. 
[33] A. M. van Dijk and A. W. Lazonder, "Scaffolding students' use of learner-generated content in a technology-enhanced inquiry learning environment," Interactive learning environments, vol. 24, no. 1, pp. 194-204, 2016. https://doi.org/10.1080 $/ 10494820.2013 .834828$

[34] Z. Belkhamza, M. Niasin, and A. Faris, "The Effect of Privacy Concerns on Smartphone App Purchase in Malaysia: Extending the Theory of Planned Behavior," International Journal of Interactive Mobile Technologies, vol. 11, no. 5, 2017. https://doi.org/10.3 991/ijim.v11i5.6961

[35] I. Ajzen, "The theory of planned behavior," Organizational behavior and human decision processes, vol. 50, no. 2, pp. 179-211, 1991. https://doi.org/10.1016/0749-5978(91)90020-t

[36] K. Glanz, B. K. Rimer, and K. Viswanath, Health behavior and health education: theory, research, and practice. John Wiley \& Sons, 2008.

[37] L. A. M. Mendes Filho, F. B. Tan, and A. Mills, "User-generated content and travel planning: An application of the theory of planned behavior," Revista Brasileira de Pesquisa em Turismo, vol. 6, no. 3, pp. 280-289, 2012. https://doi.org/10.7784/rbtur.v6i3.543

[38] I. Ajzen, "Perceived behavioral control, self-efficacy, locus of control, and the theory of planned behavior 1," Journal of applied social psychology, vol. 32, no. 4, pp. 665-683, 2002. https://doi.org/10.1111/j.1559-1816.2002.tb00236.x

[39] T. J. Madden, P. S. Ellen, and I. Ajzen, "A comparison of the theory of planned behavior and the theory of reasoned action," Personality and social psychology Bulletin, vol. 18, no. 1, pp. 3-9, 1992. https://doi.org/10.1177/0146167292181001

[40] H. Ajjan and R. Hartshorne, "Investigating faculty decisions to adopt Web 2.0 technologies: Theory and empirical tests," The internet and higher education, vol. 11, no. 2, pp. 71-80, 2008. https://doi.org/10.1016/j.iheduc.2008.05.002

[41] A. Sadaf, T. J. Newby, and P. A. Ertmer, "Exploring factors that predict preservice teachers' intentions to use Web 2.0 technologies using decomposed theory of planned behavior," Journal of Research on Technology in Education, vol. 45, no. 2, pp. 171-196, 2012. https://doi.org/10.1080/15391523.2012.10782602

[42] M. G. Morris, V. Venkatesh, and P. L. Ackerman, "Gender and age differences in employee decisions about new technology: An extension to the theory of planned behavior," IEEE transactions on engineering management, vol. 52, no. 1, pp. 69-84, 2005. https://doi.org/10.1109/tem.2004.839967

[43] P. Kline, An easy guide to factor analysis. Routledge, 2014.

[44] R. Yadav and G. S. Pathak, "Young consumers' intention towards buying green products in a developing nation: Extending the theory of planned behavior," Journal of Cleaner Production, vol. 135, pp. 732-739, 2016. https://doi.org/10.1016/j.jclepro.2016.06.120

[45] P. Ifinedo, "Understanding information systems security policy compliance: An integration of the theory of planned behavior and the protection motivation theory," Computers \& Security, vol. 31, no. 1, pp. 83-95, 2012. https://doi.org/10.1016/j.cose.2011.10.007

[46] V. L. Greene and E. G. Carmines, "Assessing the reliability of linear composites," Sociological methodology, vol. 11, pp. 160-175, 1980. https://doi.org/10.2307/270862

[47] J. Cheon, S. Lee, S. M. Crooks, and J. Song, "An investigation of mobile learning readiness in higher education based on the theory of planned behavior," Computers \& education, vol. 59, no. 3, pp. 1054-1064, 2012. https://doi.org/10.10 16/j.compedu.2012.04.015

[48] D. Hooper, J. Coughlan, and M. Mullen, "Structural equation modelling: Guidelines for determining model fit," Articles, p. 2, 2008. 
[49] C.-L. Hsu and J. C.-C. Lin, "Acceptance of blog usage: The roles of technology acceptance, social influence and knowledge sharing motivation," Information \& management, vol. 45, no. 1, pp. 65-74, 2008. https://doi.org/10.1016/j.im.2007.11.001

[50] C. C. Wang, S. K. Lo, and W. Fang, "Extending the technology acceptance model to mobile telecommunication innovation: The existence of network externalities," Journal of Consumer Behaviour: An International Research Review, vol. 7, no. 2, pp. 101-110, 2008. https://doi.org/10.1002/cb.240

[51] B. A. Miraja, S. F. Persada, Y. T. Prasetyo, P. F. Belgiawan, and A. P. Redi, "Applying Protection Motivation Theory to Understand Generation Z Students Intention to Comply with Educational Software Anti Piracy Law," International Journal of Emerging Technologies in Learning (iJET), vol. 14, no. 18, pp. 39-52, 2019. https://doi.org/10.3 991/ijet.v14i18.10973

[52] S. Papadakis and M. Kalogiannakis, "Mobile educational applications for children: what educators and parents need to know," International Journal of Mobile Learning and Organisation, vol. 11, no. 3, pp. 256-277, 2017. https://doi.org/10.1504/ijmlo.2017.085338

[53] M. Kalogiannakis and S. Papadakis, "An evaluation of Greek educational Android apps for preschoolers," in proceedings of the 12th Conference of the European Science Education Research Association (ESERA), Research, Practice and Collaboration in Science Education, Dublin City University and the University of Limerick, Dublin, Ireland, 2017, pp. 21-25.

[54] S. Papadakis, M. Kalogiannakis, and N. Zaranis, "Designing and creating an educational app rubric for preschool teachers," Education and Information Technologies, vol. 22, no. 6, pp. 3147-3165, 2017. https://doi.org/10.1007/s10639-017-9579-0

[55] Y. K. Usluel and S. G. Mazman, "Adoption of Web 2.0 tools in distance education," Procedia-Social and Behavioral Sciences, vol. 1, no. 1, pp. 818-823, 2009. https://doi.org/10.1016/j.sbspro.2009.01.146

\section{$7 \quad$ Authors}

Satria Fadil Persada, Ph.D (Satria) research interest is studying the behaviour of person's in the perspective of consumers and organization. Satria' research interest is also related to proenvironmental behaviour.

Jeremy Ivanosky (Jeremy) is currently studying business management for a bachelor degree in the Department of Business Management, Institut Teknologi Sepuluh Nopember (ITS). Jeremy's main research interest is in the user-generated content.

Bobby Ardiansyah Miraja (Bobby) is currently studying business management for a bachelor degree in the Department of Business Management, Institut Teknologi Sepuluh Nopember (ITS). Bobby's main research interest is in the technology and human resources area.

Reny Nadlifatin, Ph.D studies focuses on technology acceptance models, specifically on behavior towards information technology

Ilma Mufidah, Ph.D research interest is in human factors and human perceptions.

Jacky Chin, Ph.D research interest is in the field of behaviour user on technology and system

A.A.N. Perwira Redi, Ph.D research interest is in the field of industrial management.

Article submitted 2019-09-12. Resubmitted 2019-11-22. Final acceptance 2019-11-22. Final version published as submitted by the authors. 